\section{Identifying barriers to successful research during medical school}

\author{
Chayan Chakraborti, ${ }^{1}$ \\ Daniel J. Bourgeois III,' \\ Elizabeth Gleeson, ${ }^{1}$ William Gunderson ${ }^{2}$ \\ 'Department of Medicine, Tulane \\ University School of Medicine, New \\ Orleans, LA; ${ }^{2}$ Department of Medicine, \\ Oregon Health and Science University, \\ Portland, OR, USA
}

\section{Abstract}

Despite an increase in the number of formal research courses and the support services that institutions provide, the success that students achieve is modest suggesting the involvement of other factors. The authors seek to determine the extent to which barriers and resources affect the ability for students to be successful in research endeavors. The authors distributed a cross-sectional survey via the Internet to members of the American Medical Association-Medical Student Section (AMAMSS) and the American Medical Student Association. The authors also distributed a paper version of the survey during the AMAMSS national conference in San Diego, CA, October 2010 . The primary outcome was selfidentified successful research. The authors also assessed the supportive factors and barriers the respondents faced. 422 students completed the survey and identified having mentorship (OR 1.38, 95\% CI 1.11-1.60), student funding (OR 1.52, 95\% CI 1.26-1.69), and having an office or director of student research (OR 1.52, 95\% CI 1.26-1.70) as factors associated with successfully publishing as a medical student. Barriers to success in student research included being unaware what research occurs locally (OR 1.36, 95\% CI 1.051.76), lacking faculty mentors (OR 1.45, 95\% CI 1.07-1.95), and lack of a research office/coordinator (OR 1.53, 95\% CI 1.18-2.00). The effects of the barriers were not offset by the research curricula provided. To improve the success of medical students involved in involved in research, academic medical institutions must address barriers directly in addition to offering curricula in research methods.

\section{Introduction}

In July 2008, the Liaison Committee on Medical Education (LCME) recognized the need for earlier exposure to research with updated guidelines that described a change from a simple recommendation for research to scholarly activity as a requirement for all medical students. ${ }^{1}$ This poses a challenge for medical students, as research exposure may not occur until late in training ${ }^{2}$ and this exposure to research is at best described as inconsistent between programs. ${ }^{3}$ The problem is widespread as even in residency, few programs provide a dedicated curriculum and possess the resources needed to support research, ${ }^{2,4}$ despite the fact that such support provided to researchers advances the expansion of professional skills. ${ }^{5-8}$

An environment supportive of research can lead to increased productivity. ${ }^{6,9,10}$ Mentorship appears to be an especially critical form of support as it can enhance personal and professional development, ${ }^{11}$ career satisfaction, ${ }^{11}$ medical student career advancement, ${ }^{12,13}$ and research efforts. ${ }^{9,10,13,14}$ Thus, careful attention to the creation of a supportive environment through the use of a needs assessment may provide the greatest influence on the development of qualified medical researchers. ${ }^{6,9,15-19}$

To develop this needs assessment, we surveyed medical students with the aim of identifying factors that allowed for successful student research and barriers preventing scholarly activities in light of their institution's attempts at providing support. It may be that formal curricula designed to engage students in research are still off the mark, and students in institutions with well-developed curricula still face barriers. Identifying, characterizing, and prioritizing these barriers that prevent students from developing research skills may provide insight as to why these curricula do not result in more promising outcomes.

\section{Materials and Methods}

\section{Survey creation and content}

The survey instrument was adapted from a similar survey that examined research barriers for internal medicine residents. ${ }^{6}$ We refined our survey through a review of the literature and through focus group discussions with medical students who have been both successful and unsuccessful at research projects. The 10-item survey was organized into 4 topics areas: i) amount of research undertaken, ii) timing of research, iii) support provided by institution, and iv) barriers as well as general student characteristics. In inquiring about institutional support, students were asked about elements of formal research curriculum and mentoring programs, as well as mandatory requirements for scholarly projects.
Correspondence: Chayan Chakraborti, Department of Medicine, Tulane University School of Medicine, 1430 Tulane Avenue, SL-16, New Orleans, LA 70112, USA

Tel. +1.504.988.7518 - Fax: +1.509.472.3758.

E-mail: cchakrab@tulane.edu

Key words: research, medical school, barriers.

Funding/Support: a Medical Education Mini-Grant provided by the Tulane University School of Medicine Office of Medical Education supported a portion of Dr. Chakraborti's research. The funding agency (Tulane Office of Medical Education) had no role in the design and conduct of the study.

Contributions: CC, data collection, analysis and interpretation, study conception and design, manuscript drafting, supervision; DJB, EG, data acquisition, analysis and interpretation, manuscript drafting, critical revision; WG, study conception and design, statistical analysis, critical revision of the manuscript.

Conflict of interest: there is no conflict of interest with this research.

Received for publication: 30 September 2011. Revision received: 28 December 2011. Accepted for publication: 3 January 2012.

This work is licensed under a Creative Commons Attribution NonCommercial 3.0 License (CC BYNC 3.0).

() Copyright C. Chakraborti et al., 2012

Licensee PAGEPress srl, Italy

Medical Education Development 2012; 2:e2

doi:10.4081/med.2012.e2

\section{Survey administration}

We created the survey to examine patterns of scholarly activities of medical students. An online version of this survey was distributed to medical student members of the American Medical Association (AMA) Medical Student Section and the American Medical Student Association. Through prior agreement, these two organizations agreed to distribute the survey link via email correspondence with their memberships. In addition, a paper version of this survey was distributed at the student section of 2010 American Medical Association national meeting. All responses were anonymous and kept confidential. The Tulane University School of Medicine Institutional Review Board approved this study after expedited review.

\section{Data analysis}

Survey responses were based on a 5-point Likert scale and dichotomized and analyzed as proportions using the Fischer's exact test. ANOVA and Wilcoxon rank sum tests were 
used to verify significance between categories in unadjusted analyses. Spearman correlations and multiple logistic regression analysis was used to calculate the odds ratios for factors for and barriers to successful research. A sample size of 134 resulted in a power of 0.80 to detect an anticipated effect size $\left(\mathrm{r}^{2}\right)$ of 0.10 . All analyses were two-tailed and used an $\alpha$-level of 0.05 . Data were analyzed using Stata 9.2 (STATA Corporation, College Station, TX, 2007).

\section{Results}

\section{Descriptive results}

Out of 422 respondents, $51 \%$ were male and $49 \%$ female. To identify the geographic distribution, we used the AMA regions as a starting point. ${ }^{20}$ Due to small numbers of respondents from certain areas, we combined the subregions (ex: Mountain and Pacific were combine into West). The geographical distribution and demographic information can be found in Table 1. The table also lists the mean number of publications per medical school year. A total of 183 respondents (43.4\%) reported publishing during medical school and the majority (57\%) of these, did so in the first two years of school. Most students (71\%) were also able to do research in this same time period compared to the later years (24\%).

\section{Individual factors}

Students in our sample reported a variety services provided by their institutions in support of research (Table 2). Most commonly (62\%) students felt that mentors were available and that institutions provided help getting started in some way (53.9\%). Only $19.4 \%$ of respondents reported having a mandatory course on research methods, while $28.7 \%$ reported that an elective research course was available at their institution. A similar number of students (19.2\%) reported that a scholarly project was a graduation requirement. However, having a mandatory research course or a scholarly project graduation requirement were not significantly associated with publications, $\mathrm{r}^{2} \quad 0.06$ $(\mathrm{P}=0.64)$ and $\mathrm{r}^{2} 0.11(\mathrm{P}=0.50)$, respectively.

Multiple logistic regression showed that significant factors for successfully publishing during medical school included having mentorship, student funding, and having an office or director of student research (odds ratios and 95\% confidence intervals available in Table 2). In all, $60 \%$ of the students surveyed reported that they felt that their institution had adequately prepared them to be involved in research. However the mean number of publications for people who did not feel prepared to do research (1.49, SD 1.71) was not significantly different from the mean number of pub- lications of those who reported feeling prepared (1.33, SD 1.67), $\mathrm{P}=0.192$.

\section{Barriers}

Table 3 shows the frequency of barriers as reported by the respondents. In the unadjusted analyses using Fischer's exact tests, all barriers listed in Table 3 achieved significance in both students who reported feeling prepared for research and those who reported feeling unprepared with the exceptions of lack of student interest in research and lack of student time. We identified a number of significant barriers to publishing. Being unaware what research occurs locally (OR 1.36, 95\% CI 1.05$1.76, \mathrm{P}=0.02)$, lacking faculty mentors ( $\mathrm{OR}$ $1.45,95 \%$ CI 1.07-1.95, $\mathrm{P}=0.02)$, and lack of a research office/coordinator (OR 1.53, 95\% CI
1.18-2.0, $\mathrm{P}=0.001$ ), were barriers that were associated with not publishing (Table 3 ). In addition, students who felt that their institution prepared them for research reported significantly fewer number of barriers (mean 5.3, SD 2.5), than students who felt unprepared, (mean 7.0, SD 2.6), $\mathrm{P}<0.001$.

\section{Curricular factors}

Several survey questions inquired about curricular content related to research. The majority of students reported good exposure to biostatistics and literature searching, while research ethics $(1.50,95 \%$ CI 1.14-1.71, $\mathrm{P}=0.013)$ and instruction navigating the IRB process (1.61 95\% CI 1.32-1.78, P=0.001) were associated with success in publishing (Table 4). However, the total number of curricular

Table 1. Demographics and respondent characteristics.

\begin{tabular}{|c|c|c|c|c|}
\hline Region & States included (USA) & $N(\%)$ & Male $\%^{*}$ & Female $\%^{*}$ \\
\hline East & $\begin{array}{l}\text { CT, MA, ME, NH, RI, VT, NJ, NY, } \\
\text { PA, DE, VA, WV, MD, DC }\end{array}$ & $68(16.2 \%)$ & $56 \%$ & $42 \%$ \\
\hline South & $\begin{array}{l}\text { FL, GA, NC, SC, AL, KY, MS, } \\
\text { TN, LA, TX }\end{array}$ & $231(55.1 \%)$ & $49 \%$ & $50 \%$ \\
\hline Midwest & $\begin{array}{l}\text { MI, WI, SD, ND, MN, IL, IN, } \\
\text { OH, AR, OK, IA, KS, MO, NE }\end{array}$ & $69(16.5 \%)$ & $59 \%$ & $38 \%$ \\
\hline West & $\begin{array}{l}\text { AZ, CO, ID, MT, NM, NV, UT, } \\
\text { WY, AK, CA, HI, OR, WA }\end{array}$ & $54(12.8 \%)$ & $63 \%$ & $33 \%$ \\
\hline $\begin{array}{l}\text { Medical school } \\
\text { (MS)year }\end{array}$ & $\begin{array}{l}\text { Mean \# publications } \\
\text { (SD) }\end{array}$ & \# Students & Male $\%^{*}$ & Female $\%^{*}$ \\
\hline MS 1 & $1.35(1.71)$ & 109 & $52 \%$ & $45 \%$ \\
\hline MS 2 & $0.99(1.41)$ & 167 & $58 \%$ & $29 \%$ \\
\hline MS 3 & $1.67(1.72)$ & 90 & $52 \%$ & $47 \%$ \\
\hline MS 4 & $2.00(1.82)$ & 51 & $43 \%$ & $53 \%$ \\
\hline$>\operatorname{MS} 4$ & $3.60(2.88)$ & 5 & $80 \%$ & $20 \%$ \\
\hline Total & $1.38(1.68)$ & 422 & $54 \%$ & $45 \%$ \\
\hline
\end{tabular}

"Percents do not equal $100 \%$ as some respondents failed to indicate gender.

Table 2. Medical institution resources and their association with successful publishing.

\begin{tabular}{|c|c|c|}
\hline $\begin{array}{l}\text { Resource } \\
\text { provided }\end{array}$ & $\begin{array}{c}\text { N }(\%) \text { indicating } \\
\text { resource was } \\
\text { provided }\end{array}$ & $\begin{array}{l}\text { Correlation } \\
\text { coefficient } \\
\left(\mathrm{r}^{2}\right)\end{array}$ \\
\hline
\end{tabular}

\begin{tabular}{lcccc} 
Protected time & $189(44.9)$ & 0.10 & - & - \\
Help getting started & $227(53.9)$ & 0.14 & - & - \\
\hline Mentors & $261(62.0)$ & 0.14 & $1.38(1.11-1.60)$ & 0.04 \\
Funding & $159(37.8)$ & 0.21 & $1.52(1.26-1.69)$ & 0.001 \\
\hline Structured courses & $88(20.9)$ & 0.21 & - & - \\
Tech support & $115(27.3)$ & 0.13 & - & - \\
\hline Special recognition & $147(34.9)$ & 0.06 & - & - \\
Office of research & $128(30.4)$ & 0.12 & $1.53(1.26-1.70)$ & 0.001 \\
\hline EMR & $72(17.1)$ & 0.13 & - & - \\
Mandatory research course & $81(19.4)$ & 0.06 & - & - \\
\hline Scholarly activity graduation & $80(19.2)$ & 0.11 & - & - \\
requirement & & & & \\
\hline
\end{tabular}

"Using multiple logistic regression to control for all variables only these factors were associated with increased odds of publishing (Cl=confidence interval). ${ }^{\circ} \mathrm{P}<0.05$. 
components found in a research curriculum correlated inversely with the number of barriers reported by students $\left(\mathrm{r}^{2}=-0.45, \mathrm{P}=0.018\right)$.

\section{Discussion}

Medical schools now face the burden of exposing medical students to research; ${ }^{21}$ the systems that are in place to support these endeavors must be examined. The published literature suggests that a minority of medical schools provide formal student research curricula..$^{5,19,22}$ Two recent articles identified between 15 and 25 formal mandatory and elective scholarly concentration programs. ${ }^{5,22} \mathrm{~A}$ decade ago an informal tally accounted for 11 such programs. ${ }^{19}$ While the number of scholarly programs may have doubled in the last 10 years, the proportion of students who are involved in research and who are successful remains largely unchanged. Our study found that approximately one-third of the students surveyed had published during a 4-year M.D. or D.0. degree-granting program, which compares favorably to an earlier study. ${ }^{9}$ As this study is over 20 years old and against the background of LCME requirements encouraging increased attention to research, the numbers of students exposed to research should be much higher. The support provided by academic institutions may need to be more extensive.

These efforts to expose medical students to research range from highly dedicated, longterm programs such as combined $\mathrm{MD} / \mathrm{PhD}$ tracks and year-long research fellowships to relying upon a student's internal motivation to seek out research. ${ }^{519}$ Comparisons between these research curricula found that publication success ranged from $8 \%$ to $85 \%$ of students involved in research. ${ }^{5}$ We submit that this variation depends in large part on the barriers students face with respect to research and not solely on the presence or absence of scholarly project curricula. Moreover, this variation in curricular strategy is concerning, though recent studies have examined the effectiveness of research curricula albeit from the perspective of faculty and administration. ${ }^{22}$ Even in institutions with robust research curricula, challenges persist, though these seem to amount to perennial problems of available time and funding according to faculty. ${ }^{23,24}$

We believe that special attention should be placed on those factors as perceived by students. While many respondents reported feeling prepared by their institution to do research, our study shows that feeling prepared was not equivalent to being prepared. Factors such as adjusting the curricula to more easily provide protected time for research and awarding special recognition for scholarly projects demonstrates a commitment to promoting student research from medical school administrations. While funding will always be a challenge, institutions that organize research efforts under an office or director of research further supports this commitment and centralizes the dissemination of grants, awards, and requests for proposals. These institutional efforts must be championed and reexamined; successes should be celebrated. Institutions possessing recognition or research time should assess whether their students are aware of these incentives and ensure that offices of research are not underutilized.

Institutions that possessed these resources frequently required that students either participate in a mandatory course on research and/or required a scholarly project prior to graduation. Neither of these conditions correlated with greater success in publication. We submit that this is not due the quality of the research curriculum, but that these curricula/institutions did not also address barriers to research. For example, an extensive research course could well teach research design and methodology, analysis, and medical writing, but if a student finds it difficult to discover what research is occurring in the institution, or is unable to match with a mentor, the course may be successful but the student's research aspirations are unrealized. Indeed, our study reaffirms that a research course is necessary but not sufficient, and an updated faculty database of research mentors and their content areas would serve to minimize barriers to a greater extent.

The only curricular content items associated with publishing (albeit minimally) were research ethics and Institutional Review Board navigation. The report of curricular items may have been somewhat heterogeneous in that the survey only broadly defined categories, i.e., research design might have been referred to differently. In addition, although the survey asked whether research course components were somewhat- or well-taught, no objective measure of well-taught was described. We suspect that both students who were successful and those who are not successful or not interested in research were equal recipients of topics such as biostatistics, literature searching, and research design as these are commonly

Table 3. Factors reported by students and their association with being unsuccessful at publishing.

\begin{tabular}{|c|c|c|c|c|}
\hline Barriers & $\begin{array}{l}\text { N (\%) Agreeing } \\
\text { or strongly } \\
\text { agreeing }\end{array}$ & $\begin{array}{l}\text { Correlation } \\
\text { coefficient } \\
\left(\mathrm{r}^{2}\right)\end{array}$ & OR $(95 \% \mathrm{CI})^{*}$ & P-value \\
\hline Difficulty getting started & $339(80.3)$ & 0.02 & - & - \\
\hline Difficulty finding projects & $260(61.6)$ & 0.04 & - & - \\
\hline Unaware of what research occurs & $278(65.9)$ & $0.10^{\circ}$ & $1.36(1.05-1.76)$ & 0.02 \\
\hline Difficulty finding faculty mentors & $149(35.3)$ & $0.18^{\circ}$ & $1.45(1.07-1.95)$ & 0.02 \\
\hline Student interest in research & $149(35.3)$ & 0.03 & - & - \\
\hline Lack of time (student) & $326(77.3)$ & 0.06 & - & - \\
\hline Lack of time (faculty) & $173(41.0)$ & 0.10 & - & - \\
\hline Lack of funding & $230(54.5)$ & 0.08 & - & - \\
\hline Lack of structured curriculum & $284(67.3)$ & 0.03 & - & - \\
\hline Lack of technical support & $156(37.0)$ & 0.10 & - & - \\
\hline Lack of research office & $177(41.9)$ & $0.12^{\circ}$ & $1.53(1.18-2.0)$ & 0.001 \\
\hline
\end{tabular}

Table 4. Curriculum content items and their affect on successful publishing.

\begin{tabular}{lcccc}
$\begin{array}{l}\text { Content area } \\
\text { or item }\end{array}$ & $\begin{array}{c}\text { N }(\%) \text { Respondents } \\
\text { reporting content } \\
\text { somewhat or } \\
\text { thoroughly taught }\end{array}$ & $\begin{array}{c}\text { Correlation } \\
\text { coefficient } \\
\left(\mathrm{r}^{2}\right)\end{array}$ & OR (95\% CI)* & P-value \\
Research design & $188(44.6)$ & -0.01 & - & - \\
Research ethics & $234(55.5)$ & $0.04^{\circ}$ & $1.50(1.14-1.71)$ & 0.013 \\
\hline Navigating IRB process & $103(24.4)$ & $0.07^{\circ}$ & $1.61(1.32-1.78)$ & 0.001 \\
Biostatistics & $312(73.9)$ & 0.06 & - & - \\
\hline Literature searching & $307(72.8)$ & 0.01 & - & - \\
Research writing & $121(28.7)$ & 0.04 & - & - \\
\hline
\end{tabular}

"Using multiple logistic regression to control for all variables only these factors were associated with increased odds of publishing $(\mathrm{Cl}=\mathrm{con}-$ fidence interval).

${ }^{\circ} \mathrm{P}<0.05$. 
included in evidence-based medicine courses. Students who are already involved in a research project would most likely be required to take the Collaborative Institutional Training Initiative (CITI) course on research ethics and may be forced to investigate the IRB submission process either formally (if available) or informally through word-of-mouth.

This study has several limitations, in particular selection bias in the study population. Those respondents completing a survey on student research are more likely to be searching for projects and accolades, especially student representatives travelling to an American Medical Association meeting conference. When inquiring what resources a medical institution provided, we did not assess the degree to which these were provided. We recognize that students were not ideal to answer some survey items (e.g., how much time faculty have for research), but we chose to focus on students' perceptions of these issues. The survey also did not take into consideration publication time lag, i.e., research that may have been done prior to medical school but published during medical school and research during medical school, but published later. Finally, students had a considerable number of comments regarding their research successes and tribulations. These qualitative results are not included here.

Support from institutions for student research does seem to be increasing. However, the research success of a student appears to be due more to an individual's determination rather than the programs in place. Barriers persist despite scholarly programs, though previous articles have described the faculty perspective on student research curricula. The ranks of future clinician-scientists will contain both dedicated clinicians as well as researchers. Thus institutions should devote efforts to minimizing barriers paying particular attention to significant barriers perceived by students. Innovations in removing barriers combined with the proliferation of formal research curricula will provide the optimal climate for fostering interest in successful student research.

\section{References}

1. LCME. New standard on clinical and translational research (ED-17-A). Available at: http://www.lcme.org/standard.htm. Accessed on December 16, 2009.

2. Levine RB, Hebert RS, Wright SM. Factors associated with citation of internal medicine residency programs for lack of scholarly activity. Teach Learn Med 2005;17:328-31.

3. Hebert RS, Levine RB, Smith CG, Wright $\mathrm{SM}$. A systematic review of resident research curricula. Acad Med 2003;781:61-8.

4. Levine RB, Hebert RS, Wright SM. Resident research and scholarly activity in internal medicine residency training programs. J Gen Intern Med 2005;20:155-9.

5. Bierer SB, Chen HC. How to measure success: The impact of scholarly concentrations on students-a literature review. Acad Med 2010;85:438-52.

6. Rivera JA, Levine RB, Wright SM. Completing a scholarly project during residency training. Perspectives of residents who have been successful. J Gen Intern Med 2005;20:366-9.

7. Buddeberg-Fischer B, Herta KD. Formal mentoring programmes for medical students and doctors-a review of the Medline literature. Med Teach 2006;28:248-57.

8. Rose GL, Rukstalis MR, Schuckit MA. Informal mentoring between faculty and medical students. Acad Med 2005;80:344-8.

9. Segal S, Lloyd T, Houts PS, et al. The association between students' research involvement in medical school and their postgraduate medical activities. Acad Med 1990;65: 530-3.

10. Reinders JJ, Kropmans TJ, CohenSchotanus J. Extracurricular research experience of medical students and their scientific output after graduation. Med Educ 2005;39:237.

11. Sambunjak D, Straus SE, Marusic A. Mentoring in academic medicine: a systematic review. JAMA 2006;296:1103-15.

12. Osborn EH. Factors influencing students' choices of primary care or other specialties. Acad Med 1993;68:572-4.

13. Aagaard EM, Hauer KE. A cross-sectional descriptive study of mentoring relationships formed by medical students. J Gen Intern Med 2003;18:298-302.

14. Mann MP. Faculty mentors for medical students: a critical review. Med Teach 1992;14: 311-9.

15. Wakeford R, Lyon J, Evered D, Saunders N. Where do medically qualified researchers come from? Lancet 1985;2:262-5.

16. Schrier RW. Ensuring the survival of the clinician-scientist. Acad Med 1997;72:589-94.

17. Kupfer DJ, Hyman SE, Schatzberg AF, et al. Recruiting and retaining future generations of physician scientists in mental health. Arch Gen Psychiatry 2002;59:657-60.

18. Brancati FL, Mead LA, Levine DM, et al. Early predictors of career achievement in academic medicine. JAMA 1992;267:1372-6.

19. Frishman WH. Student research projects and theses: Should they be a requirement for medical school graduation? Heart Dis 2001;3:140-4.

20. AMA. FREIDA program search by region. Available at: https://freida.ama-assn.org/ Freida/user/viewProgramSearch.do. Accessed on February 19, 2011.

21. Boninger M. Foreword: scholarly concentrations in the medical student curriculum. Acad Med 2010;85:403-4.

22. Green EP, Borkan JM, Pross SH, et al. Encouraging scholarship: medical school programs to promote student inquiry beyond the traditional medical curriculum. Acad Med 2010;85:409-18.

23. Boninger M, Troen $\mathrm{P}$, Green E, et al. Implementation of a longitudinal mentored scholarly project: an approach at two medical schools. Acad Med 2010;85:429-37.

24. Laskowitz DT, Drucker RP, Parsonnet J, et al. Engaging students in dedicated research and scholarship during medical school: the long-term experiences at Duke and Stanford. Acad Med 2010;85:419-28 